\title{
Comparative effects of flow vs. volume- controlled one-lung ventilation on gas exchange and respiratory system mechanics in pigs
}

Jakob Wittenstein, Martin Scharffenberg, Xi Ran, Diana Keller, Pia Michler, Sebastian Tauer, Raphael Theilen, Thomas Kiss, Thomas Bluth, Thea Koch, Marcelo Gama de Abreu* and Robert Huhle

From 4th International Symposium on Acute Pulmonary Injury and Translational Research - INSPIRES 2019

Dresden, Germany. 25-26 November 2019

\author{
* Correspondence: mgabreu@ \\ uniklinikum-dresden.de \\ Pulmonary Engineering Group, \\ Dept. of Anaesthesiology and \\ Intensive Care Medicine, University \\ Hospital Carl Gustav Carus at \\ Technische Universität Dresden, \\ Fetscherstrasse 74, 01307 Dresden, \\ Germany
}

\begin{abstract}
Background: Flow-controlled ventilation (FCV) allows expiratory flow control, reducing the collapse of the airways during expiration. The performance of FCV during one-lung ventilation (OLV) under intravascular normo- and hypovolaemia is currently unknown. In this explorative study, we hypothesised that OLV with FCV improves $\mathrm{PaO}_{2}$ and reduces mechanical power compared to volume-controlled ventilation (VCV). Sixteen juvenile pigs were randomly assigned to one of two groups: (1) intravascular normovolaemia $(n=8)$ and (2) intravascular hypovolaemia ( $n$ = 8). To mimic inflammation due to major thoracic surgery, a thoracotomy was performed, and $0.5 \mu \mathrm{g} / \mathrm{kg} / \mathrm{h}$ lipopolysaccharides from Escherichia coli continuously administered intravenously. Animals were randomly assigned to OLV with one of two sequences (60 min per mode): (1) VCV-FCV or (2) FCV-VCV. Variables of gas exchange, haemodynamics and respiratory signals were collected 20, 40 and 60 min after initiation of OLV with each mechanical ventilation mode. The distribution of ventilation was determined using electrical impedance tomography (EIT).

Results: Oxygenation did not differ significantly between modes $(P=0.881)$. In the normovolaemia group, the corrected expired minute volume $(P=0.022)$ and positive end-expiratory pressure (PEEP) were lower during FCV than VCV. The minute volume $(P \leq 0.001)$, respiratory rate $(P \leq 0.001)$, total PEEP $(P \leq 0.001)$, resistance of the respiratory system $(P \leq 0.001)$, mechanical power $(P \leq 0.001)$ and resistive mechanical power $(P \leq 0.001)$ were lower during FCV than VCV irrespective of the volaemia status. The distribution of ventilation did not differ between both ventilation modes $(P=0.103)$.

(Continued on next page)
\end{abstract} original author(s) and the source, provide a link to the Creative Commons licence, and indicate if changes were made. The images or other third party material in this article are included in the article's Creative Commons licence, unless indicated otherwise in a credit line to the material. If material is not included in the article's Creative Commons licence and your intended use is not permitted by statutory regulation or exceeds the permitted use, you will need to obtain permission directly from the copyright holder. To view a copy of this licence, visit http://creativecommons.org/licenses/by/4.0/. 
(Continued from previous page)

Conclusions: In a model of OLV in normo- and hypovolemic pigs, mechanical power was lower during FCV compared to VCV, without significant differences in oxygenation. Furthermore, the efficacy of ventilation was higher during FCV compared to VCV during normovolaemia.

Keywords: OLV, FCV, VILI, Hypoxemia, Thoracic surgery, Intravascular hypovolaemia, Normovolaemia, Mechanical power, Resistive mechanical power

\section{Background}

During one-lung ventilation (OLV) the incidence of hypoxemia can be as high as $10 \%$ and may lead to adverse outcomes [1]. Hypoxemia results mainly from the formation of atelectasis in the dependent lung, which increases the intrapulmonary shunt and alveolar dead space [2]. Atelectasis can lead also to cyclic collapse and reopening of lung areas, the so-called atelectrauma [3]. Furthermore, in the presence of atelectasis, the tidal volume is distributed across a reduced lung volume, possibly resulting in hyperdistension of lung zones, or volutrauma [4]. Atelectrauma and volutrauma can increase the transfer of energy per time from the ventilator to the lungs (mechanical power [5]), which might result in ventilator-induced lung injury (VILI) [6]. In fact, the risk of VILI is increased during thoracic procedures compared with non-thoracic procedures [7].

Volume-controlled mechanical ventilation (VCV) is frequently used during surgery [8], but this mode does not limit the airflow during expiration. Un-controlled expiratory flow combined with avalanche-like lung closure dynamics [9] favours the formation of atelectasis. Flow-controlled ventilation (FCV) is a new mode of mechanical ventilation where the flow is controlled during both inspiration and expiration, and phases of zero flow are avoided. During two-lung ventilation in pigs, FCV increased oxygenation in non-injured [10] and injured lungs [11], but the performance of FCV during OLV has not been investigated. Theoretically, FCV would also reduce the mechanical power [12], but, to our knowledge, this effect has not been demonstrated.

In the present study, we aimed at determining the effects of FCV and VCV on gas exchange and respiratory mechanics during OLV in pigs. Since hypovolaemia may blunt the hypoxic pulmonary vasoconstriction [13], the performance of these mechanical ventilation modes was investigated during normovolaemia and hypovolaemia. In this explorative study, we hypothesised that FCV improves oxygenation, and reduces the mechanical power, as compared to VCV during OLV.

\section{Methods}

The Institutional Animal Care and Welfare Committee and the Government of the State of Saxony, Germany (DD24.1-5131/449/71), approved the study, which was performed as the secondary protocol of another study on pulmonary perfusion. All animals received humane care in compliance with the Principles of Laboratory Animal Care formulated by the National Society for Medical Research and the US National Academy of Sciences Guide for the Care and Use of Laboratory Animals and complied with relevant aspects of the ARRIVE guidelines. Animals were kept at controlled temperature and light-dark cycle with free access to water and food. 


\section{Experimental protocol}

The time course of the experiments is presented in Fig. 1. Sixteen female pigs (German landrace, weighing 35 to $49 \mathrm{~kg}$, Danish Specific Pathogen Free Certification, www.spf. $\mathrm{dk})$ were intramuscularly pre-medicated with midazolam $(1 \mathrm{mg} / \mathrm{kg})$ and ketamine $(10$ $\mathrm{mg} / \mathrm{kg}$ ). Intravenous anaesthesia was induced and maintained with midazolam (bolus 0.5 to $1 \mathrm{mg} / \mathrm{kg}$, followed by $1 \mathrm{mg} / \mathrm{kg} / \mathrm{h}$ ) and ketamine (bolus 3 to $4 \mathrm{mg} / \mathrm{kg}$, followed by $15 \mathrm{mg} / \mathrm{kg} / \mathrm{h}$ ). Muscle paralysis was achieved with atracurium (bolus 3 to $4 \mathrm{mg} / \mathrm{kg}$, followed by $3 \mathrm{mg} / \mathrm{kg} / \mathrm{h}$ ). Lungs were initially ventilated in volume-controlled mode using the following settings: fraction of inspired oxygen $\left(\mathrm{F}_{\mathrm{I}} \mathrm{O}_{2}\right)$ of 1.0, tidal volume $\left(\mathrm{V}_{\mathrm{T}}\right)$ of $6 \mathrm{~mL} / \mathrm{kg}$, positive end-expiratory pressure (PEEP) of $5 \mathrm{cmH}_{2} 0$, inspiratory: expiratory (I:E) ratio of $1: 1$, constant gas flow of $25 \mathrm{~L} / \mathrm{min}$, and respiratory rate (RR) adjusted to achieve $\mathrm{PaCO}_{2}=35-45 \mathrm{mmHg}$.

All skin incisions were preceded by infiltration of $2-5 \mathrm{~mL}$ lidocaine $2 \%$. After surgical preparation of the right internal carotid artery, a PICCO catheter $(20 \mathrm{~cm}$; Pulsion Medical Systems SE, Feldkirchen, Germany) was inserted and the mean arterial pressure (MAP) continuously monitored. A 7.5 Fr. pulmonary artery catheter (Opticath, Abbott, Abbott Park, USA) to measure cardiac output (CO), and mean pulmonary artery pressure (MPAP) was advanced through an $8.5 \mathrm{Fr}$. sheath, placed in the right external jugular vein until typical pulmonary arterial pressure waveforms were observed. Urine was collected with a bladder catheter inserted through a median mini-laparotomy.

In order to measure regional transpulmonary pressures, three custom-made pressure sensors were attached to the parietal pleura in the following regions of the left hemithorax: (1) ventral (4-5th rib parasternal), (2) dorsal (4-5th rib paravertebral), and (3) caudal (8-9th rib paravertebral) as described in detail before (Kiss et al., 2019). Briefly, animals were positioned in the right lateral decubitus position. The lungs were separated introducing a left-sided double-lumen tube (39 Fr., Silbroncho Fuji, Tokyo, Japan) through a tracheotomy, with the bronchial tip placed into the left main bronchus. Pressure sensors were placed using video-assisted thoracoscopy (Thoracoscopy Set, Karl Storz, Tuttlingen, Germany). A thoracic drain was placed and connected to a surge tank.

To mimic thoracic surgery conditions a right-sided thoracotomy was performed between the medial-clavicular and the anterior axillary line in the 4-5th intercostal space and a rib spreader placed. Furthermore, systemic inflammation was induced by

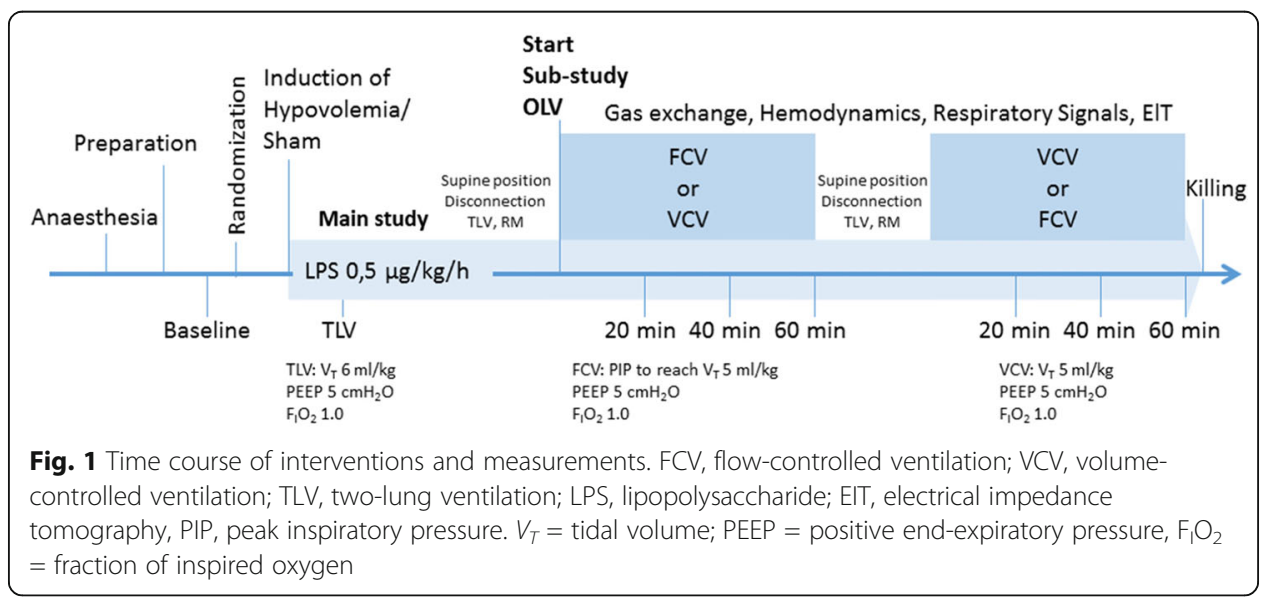


continuous administration of $0.5 \mu \mathrm{g} / \mathrm{kg} / \mathrm{h}$ purified lipopolysaccharides from Escherichia coli O111:B4 (SIGMA Aldrich, St. Louis, USA) through the central venous line.

The intravascular volume was initially maintained with a crystalloid solution (E153, Serumwerk Bernburg AG, Bernburg, Germany) at a rate of $5 \mathrm{~mL} / \mathrm{kg} / \mathrm{h}$. Norepinephrine was used to maintain a mean arterial pressure of at least $60 \mathrm{mmHg}$ throughout the experiments.

Animals were then randomised to either the normo- or the hypovolaemia group. For induction of hypovolaemia, $25 \%$ of the calculated blood volume, estimated as $70 \mathrm{~mL} /$ $\mathrm{kg}$ [14], was drawn from the central venous catheter. Thereafter, randomisation was performed and animals were placed in the left lateral decubitus position and submitted to one of two sequences, namely FCV-VCV or VCV-FCV (60 min per mode, crossover). To reset lung history, animals were put on supine position, disconnected from the ventilator, two-lung ventilation resumed, and an alveolar recruitment manoeuvre performed before the start of each ventilation mode.

\section{One lung ventilation}

For VCV $\mathrm{V}_{\mathrm{T}}$ of $5 \mathrm{~mL} / \mathrm{kg} ; \mathrm{F}_{\mathrm{I}} \mathrm{O}_{2}$ of 1.0, PEEP of $5 \mathrm{cmH}_{2} \mathrm{O}$, I:E of 1:1, a RR of 30-35 $\mathrm{min}^{-1}$ to achieve $\mathrm{pH}>7.25$ and flow of $25 \mathrm{~L} / \mathrm{min}$ were chosen. FCV was performed with the Evone Ventilator (Ventinova Medical, Eindhoven, Netherlands) using a Tritube (Ventinova Medical), placed in the bronchial lumen of the double-lumen tube with the tip of the Tritube just before the end of the double-lumen tube. Peak inspiratory pressure (PIP) was set to achieve a $\mathrm{V}_{\mathrm{T}}$ of $5 \mathrm{~mL} / \mathrm{kg}$. Furthermore, PEEP of $5 \mathrm{cmH}_{2} \mathrm{O}, \mathrm{F}_{\mathrm{I}} \mathrm{O}_{2}$ of 1.0, I:E of 1:1, and flow were chosen to reach a RR of $30-35 \mathrm{~min}^{-1}$ to achieve $\mathrm{pH}>7.25$.

\section{Measurements}

Following premedication and preparation (baseline) measurements of gas exchange, respiratory signals, haemodynamics and distribution of ventilation by electrical impedance tomography (EIT) were collected. Twenty, 40 and $60 \min \left(20^{\prime}, 40^{\prime}, 60^{\prime}\right)$ after the start of respective OLV with the randomised mode of ventilation (FCV or VCV) further measurements were performed (Fig. 1).

\section{Gas exchange, haemodynamics}

Arterial and mixed venous blood samples were analysed for respiratory gases and $\mathrm{pH}$ using a blood gas analyser (ABL 80 Flex Basic, Radiometer, Denmark). Mean arterial and pulmonary artery pressures were measured continuously, whereas $\mathrm{CO}$ was determined with a pulmonary artery catheter by means of a conventional thermodilution method. Using the PICCO catheter extravascular lung water (EVLW) (lung function), intrathoracic blood volume (ITBV) and global end-diastolic blood volume (GEDV) (cardiac preload), systemic vascular resistance (SVR) (cardiac afterload) and stroke volume (SV) were determined. The intrapulmonary shunt fraction was calculated using a standard formula.

\section{Respiratory signals and regional pleural pressure}

Airway flow was measured with the respective ventilator depending on the mode of ventilation. During VCV airway pressure was measured at the $y$-piece with a custom- 
made measurement system composed of a pressure transducer (163PC01D48-PCB, FirstSensors AG, Berlin, Germany) and respective hardware and software for amplification and recording (custom-build software written in LabVIEW, National Instruments, Austin, TX, USA). During FCV, the airway pressure signal was measured at the proximal tip of the Tritube and recorded by the Evone ventilator. The difference of location of airway pressure measurement between both ventilation modes was compensated before calculation of respiratory variables and respiratory mechanics: The pressure drop $\Delta P$ over the double-lumen tube was measured at different levels of airway flow during ventilation of an artificial lung. The determined flow $(F)$ and $\Delta P$ values were fit to the Rohrer equation $\Delta P(F)=K_{1} \cdot F+K_{2} \cdot F^{2}[15,16] . \Delta P$, as calculated from this equation during the experiments, was then subtracted from measured airway pressure during VCV.

Airway/tracheal pressure $(P)$, airflow, and volume were recorded for $5 \mathrm{~min}$ at the end of each time point. Airway pressure and pleural pressure signals in ventral, dorsal, and caudal regions were obtained from pressure transducers [17] (163PC01D48-PCB, FirstSensors AG, Berlin, Germany). Respiratory system compliance and resistance were determined using multiple linear regression of the linear equation of motion composed of resistance $R$ and compliance $C$ two-compartmental model of the respiratory system. Regional transpulmonary pressures in the regions (ventral, dorsal, caudal) were calculated by subtracting the respective pleural pressure from airway pressure.

Mechanical work (MW) was determined through numerical integration of the inspiratory limb of the pressure-volume curve [18]. Mechanical power per cycle was derived by multiplying $M W$ with the respiratory rate (RR): MP = MW.RR [19]. MP is the sum of the dissipated energy in the airways over the resistance (resistive MP, $\mathrm{MP}_{\text {resis }}$ ) and the energy temporarily stored in the elastic lung tissue (elastic MP, $\mathrm{MP}_{\text {elast}}$ ) [18].

The corrected expired minute volume, a surrogate of ventilation efficiency, was calculated as the measured minute volume multiplied by the arterial partial pressure of carbon dioxide $\left(\mathrm{PaCO}_{2}\right)$ divided by $40 \mathrm{mmHg}$ [20].

\section{Electrical impedance tomography}

Electrical impedance tomography (EIT) measurements were conducted with an operating frequency of $130 \mathrm{kHz}$ and 50 frames s $\mathrm{s}^{-1}$. Raw measured EIT data was $50 \mathrm{~Hz}$ filtered and reconstructed using the commercially available software of PulmoVista 500 (Drägerwerk AG \& Co. KGaA). Each EIT image of the resulting reconstructed temporal image series consisted of $32 \times 32$ pixels. EIT image reconstruction was done as described in detail by our group [21]. The global region of interest was a half-sphere covering the left hemisphere of the EIT and thus contained only the ventilated lung. This ROI was subdivided into three regions of interest (ROI) medial to lateral (independent, semi-dependent, and dependent). The difference between the end-inspiratory and end-expiratory image was taken to derive the tidal change of impedance. The ventro-dorsal centre of gravity of this tidal increase of impedance was therefore termed "centre of ventilation."

\section{Statistical analyses}

A sample size calculation was not carried out due to the exploratory nature of this substudy performed in the context of another yet unpublished experimental investigation on one-lung ventilation. Data are presented as mean and standard deviation if not 
stated otherwise. The statistical analysis was conducted with $R$ Statistical programming language Version 3.4.1 [22]. Significance was accepted at $P<0.05$. Differences between the two groups and the two ventilation modes were compared using linear mixedeffects [23], repeated measures ANOVA with with-in factors (ventilation mode and therapy time) and between factors (group and sequence of ventilation mode) [24].

\section{Results}

\section{General aspects}

Bodyweight $(P=0.805)$, total time of anaesthesia $(P=0.459)$, total time on mechanical ventilation $(P=0.544)$, cumulative doses of crystalloids $(P=0.892)$ and colloids $(P=0.154)$, total urine output $(P=0.264)$ and functional parameters at baseline did not differ significantly between normovolaemia and hypovolaemia animals. In the hypovolaemia group, 755 $\pm 80 \mathrm{~mL}$ blood was aspirated. The order of the sequence of the ventilation modes had no significant influence on any of the analysed variables.

\section{Gas exchange and haemodynamics}

$\mathrm{PaO}_{2}(P=0.881), \mathrm{PaCO}_{2}(P=0.850)$, arterial $\mathrm{pH}(P=0.652)$ and intrapulmonary shunt $(P$ $=0.097)$ did not differ between volaemia groups and ventilation modes (Fig. 2, Table 1). Furthermore, MAP, MPAP, CO, EVLW, ITB, GEDV, and SVR did not differ between groups and ventilation modes (Fig. 2, Table 1 ). In the hypovolaemia group, heart rate ( $P=$

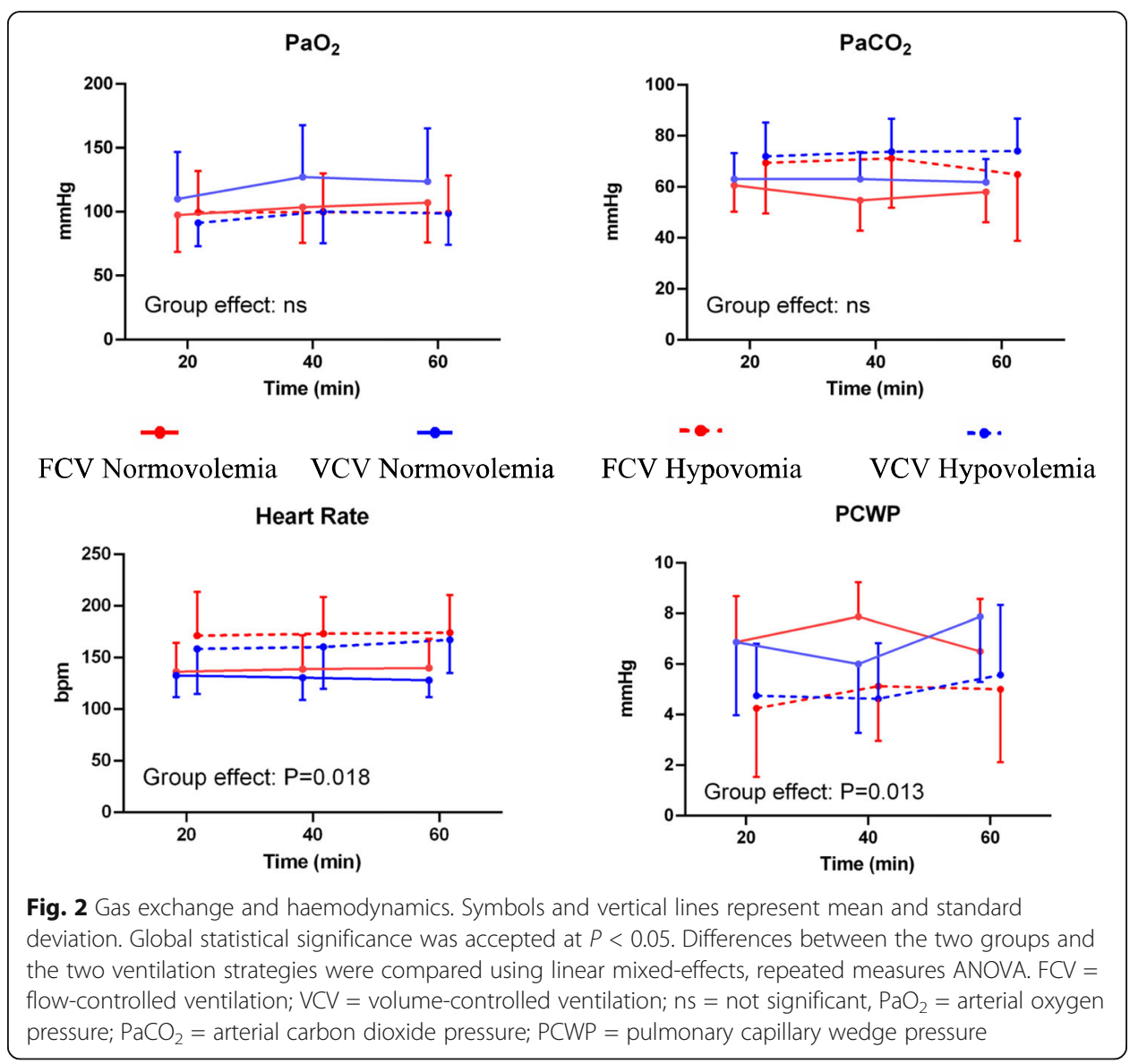


$0.018)$ and need for noradrenalin $(P=0.031)$ were higher and pulmonary capillary wedge pressure $(P=0.013)$ was lower compared with normovolaemia (Fig. 2$)$.

\section{Respiratory system variables and mechanics}

In the normovolaemia group, $\mathrm{V}_{\mathrm{T}} / \mathrm{kg}$ body weight was higher during FCV $\left(\mathrm{V}_{\mathrm{T}} 5.5 \pm 0.4\right.$ $\mathrm{ml} / \mathrm{kg})$ than VCV $\left(\mathrm{V}_{\mathrm{T}} 5.0 \pm 0.3 \mathrm{ml} / \mathrm{kg}\right)(P=0.042)$ (Table 2$)$. The minute volume $(P \leq$ $0.001)$, RR $(P \leq 0.001)$, peak tracheal pressure $\left(P_{\text {peak }}\right)(P \leq 0.001)$, total PEEP $($ PEEP + intrinsic PEEP) $(P \leq 0.001)$ (Table 2$)$ and resistance of the respiratory system $(P \leq$ 0.001 ) were lower during FCV than VCV, irrespective of the volaemia status (Table 3). The compliance of the respiratory system was lower during FCV compared with VCV $(P=0.037)$ in the hypovolaemia group while it was not different in the normovolaemia group $(P=0.05)$ (Table 3$)$. PEEP $(P \leq 0.001)$ (Table 2$)$ and corrected expired minute volume $(P=0.022)$ (Fig. 3$)$ were lower in the normovolaemia but not in the hypovolaemia group during FCV compared with VCV. In both volaemia groups, mechanical power $(P \leq 0.001)$ and resistive mechanical power $(P \leq 0.001)$ were lower during FCV than VCV, but elastic mechanical power was not different between the two modes (Fig. 3, Table 3). Regional pleural and transpulmonary pressures did not differ between groups or ventilation modes (Table 4). None of the respiratory parameters differed significantly between normovolaemia and hypovolaemia (Tables 2, 3 and 4).

\section{Regional ventilation}

Regional ventilation of the left lung did not differ significantly between FCV and VCV during both normovolaemia and hypovolaemia (Table 5).

\section{Discussion}

The main findings of the present study were that, in a model of thoracic surgery with normovolaemia as well as hypovolaemia in pigs under OLV, FCV, as compared to $\mathrm{VCV}$, reduced the mechanical power mainly due to the resistive mechanical power component without significant difference in oxygenation. Additionally, with FCV higher ventilation efficiency was achieved during normovolaemia.

To our knowledge, this is the first study reporting the use of FCV during OLV in a clinically relevant model of thoracic surgery during intravascular normo- and hypovolaemia. An important strength of this study is that we were able to reproduce key features of surgical thoracic procedures including systemic inflammation. At the dose used in this study, LPS results in a surgery-like inflammatory response, while not altering haemodynamics importantly [25]. Another strength of our study is that the investigation included scenarios of normovolaemia and moderate to severe hypovolaemia [26], both of which may occur in clinical practice [27], with different effects on hypoxic pulmonary vasoconstriction and intrapulmonary shunt [13].

Our observation that FCV did not improve oxygenation contrasts with a previous report. In pigs without lung injury, FCV increased oxygenation compared with VCV during two-lung ventilation [10]. A possible explanation for this discrepancy is that the mean tracheal pressure $\left(P_{\text {mean }}\right)$ was higher during FCV in that study [10], whereas $P_{\text {mean }}$ did not differ significantly between FCV and VCV in the present trial. Since higher mean tracheal pressures resulted in more open lung units [28], the 
Table 1 Gas exchange and haemodynamics

\begin{tabular}{|c|c|c|c|c|c|c|c|c|c|}
\hline \multirow{2}{*}{$\begin{array}{l}\text { Parameter } \\
\text { Group }\end{array}$} & \multicolumn{4}{|c|}{ Therapy } & \multicolumn{5}{|c|}{ ANOVA $(P=)$} \\
\hline & Mode & $20^{\prime}$ & $40^{\prime}$ & $60^{\prime}$ & Seq & Group & Mode & Time & Mixed \\
\hline MAP (mmHg) & & & & & 0.335 & 0.228 & 0.329 & 0.070 & 0.188 \\
\hline \multirow[t]{2}{*}{ Norm } & VCV & $80 \pm 13$ & $76 \pm 13$ & $72 \pm 14$ & & & & & \\
\hline & FCV & $74 \pm 15$ & $73 \pm 17$ & $78 \pm 28$ & & & & & \\
\hline \multirow[t]{2}{*}{ Нypo } & VCV & $65 \pm 20$ & $65 \pm 20$ & $63 \pm 22$ & & & & & \\
\hline & FCV & $69 \pm 17$ & $67 \pm 17$ & $64 \pm 17$ & & & & & \\
\hline MPAP $(\mathrm{mmHg})$ & & & & & 0.292 & 0.854 & 0.392 & 0.946 & 0.962 \\
\hline \multirow[t]{2}{*}{ Norm } & VCV & $28 \pm 8$ & $26 \pm 8$ & $27 \pm 7$ & & & & & \\
\hline & FCV & $27 \pm 8$ & $27 \pm 6$ & $27 \pm 4$ & & & & & \\
\hline \multirow[t]{2}{*}{ Нуро } & VCV & $27 \pm 7$ & $28 \pm 6$ & $28 \pm 5$ & & & & & \\
\hline & FCV & $26 \pm 7$ & $25 \pm 6$ & $25 \pm 7$ & & & & & \\
\hline CVP (mmHg) & & & & & 0.380 & 0.066 & 0.368 & 0.738 & 0.875 \\
\hline \multirow[t]{2}{*}{ Norm } & VCV & $4 \pm 4$ & $4 \pm 4$ & $5 \pm 5$ & & & & & \\
\hline & FCV & $4 \pm 3$ & $3 \pm 2$ & $4 \pm 2$ & & & & & \\
\hline \multirow[t]{2}{*}{ Нyро } & VCV & $2 \pm 1$ & $2 \pm 2$ & $2 \pm 2$ & & & & & \\
\hline & FCV & $1 \pm 2$ & $2 \pm 3$ & $1 \pm 2$ & & & & & \\
\hline $\mathrm{CO}(1 / \mathrm{min})$ & & & & & 0.744 & 0.102 & 0.456 & 0.540 & 0.369 \\
\hline \multirow[t]{2}{*}{ Norm } & VCV & $7.26 \pm 1.95$ & $7.19 \pm 1.53$ & $7.51 \pm 1.21$ & & & & & \\
\hline & FCV & $7.22 \pm 1.46$ & $7.1 \pm 1.42$ & $6.82 \pm 1.67$ & & & & & \\
\hline \multirow[t]{2}{*}{ Hypo } & VCV & $8.59 \pm 3.74$ & $8.68 \pm 2.75$ & $8.88 \pm 2.57$ & & & & & \\
\hline & FCV & $8.95 \pm 2.64$ & $8.91 \pm 2.37$ & $8.76 \pm 2.24$ & & & & & \\
\hline EVLW (mL) & & & & & 0.868 & 0.106 & 0.764 & 0.146 & 0.646 \\
\hline \multirow[t]{2}{*}{ Norm } & VCV & $446 \pm 69$ & $455 \pm 62$ & $448 \pm 61$ & & & & & \\
\hline & FCV & $438 \pm 41$ & $439 \pm 41$ & $438 \pm 44$ & & & & & \\
\hline \multirow[t]{2}{*}{ Нypo } & VCV & $559 \pm 179$ & $536 \pm 158$ & $499 \pm 127$ & & & & & \\
\hline & FCV & $562 \pm 203$ & $560 \pm 169$ & $530 \pm 180$ & & & & & \\
\hline ITBV (mL) & & & & & 0.008 & 0.210 & 0.929 & 0.879 & 0.949 \\
\hline \multirow[t]{2}{*}{ Norm } & VCV & $582 \pm 167$ & $566 \pm 141$ & $605 \pm 173$ & & & & & \\
\hline & FCV & $587 \pm 222$ & $574 \pm 240$ & $560 \pm 205$ & & & & & \\
\hline \multirow[t]{2}{*}{ Нyро } & VCV & $502 \pm 90$ & $484 \pm 88$ & $487 \pm 96$ & & & & & \\
\hline & FCV & $501 \pm 128$ & $501 \pm 118$ & $540 \pm 181$ & & & & & \\
\hline GEDV $(\mathrm{mL})$ & & & & & 0.008 & 0.220 & 0.999 & 0.974 & 0.882 \\
\hline \multirow[t]{2}{*}{ Norm } & VCV & $466 \pm 134$ & $450 \pm 114$ & $484 \pm 138$ & & & & & \\
\hline & FCV & $470 \pm 177$ & $459 \pm 192$ & $449 \pm 164$ & & & & & \\
\hline \multirow[t]{2}{*}{ Hypo } & VCV & $407 \pm 70$ & $387 \pm 70$ & $390 \pm 77$ & & & & & \\
\hline & FCV & $401 \pm 103$ & $401 \pm 94$ & $432 \pm 145$ & & & & & \\
\hline SVR $\left(\right.$ dyn* $\left.{ }^{*} / \mathrm{cm}^{5}\right)$ & & & & & 0.251 & 0.156 & 0.759 & 0.090 & 0.870 \\
\hline \multirow[t]{2}{*}{ Norm } & VCV & $955 \pm 294$ & $878 \pm 284$ & $805 \pm 236$ & & & & & \\
\hline & FCV & $1100 \pm 436$ & $858 \pm 254$ & $940 \pm 242$ & & & & & \\
\hline \multirow[t]{2}{*}{ Hypo } & VCV & $736 \pm 433$ & $726 \pm 410$ & $682 \pm 392$ & & & & & \\
\hline & FCV & $717 \pm 306$ & $720 \pm 319$ & $700 \pm 325$ & & & & & \\
\hline Noradrenalin (mg/h) & & & & & 0.607 & 0.031 & 0.912 & 0.534 & 0.790 \\
\hline \multirow[t]{2}{*}{ Norm } & VCV & $0.28 \pm 0.50$ & $0.78 \pm 1.39$ & $0.28 \pm 0.50$ & & & & & \\
\hline & FCV & $0.23 \pm 0.39$ & $0.27 \pm 0.48$ & $0.28 \pm 0.48$ & & & & & \\
\hline
\end{tabular}


Table 1 Gas exchange and haemodynamics (Continued)

\begin{tabular}{|c|c|c|c|c|c|c|c|c|c|}
\hline \multirow{2}{*}{$\begin{array}{l}\text { Parameter } \\
\text { Group }\end{array}$} & \multicolumn{4}{|c|}{ Therapy } & \multicolumn{5}{|c|}{ ANOVA $(P=)$} \\
\hline & Mode & $20^{\prime}$ & $40^{\prime}$ & $60^{\prime}$ & Seq & Group & Mode & Time & Mixed \\
\hline \multirow[t]{2}{*}{ Hypo } & VCV & $1.94 \pm 2.19$ & $2.04 \pm 2.22$ & $2.25 \pm 2.59$ & & 0.054 & & & \\
\hline & FCV & $2.12 \pm 2.15$ & $2.18 \pm 2.28$ & $2.19 \pm 2.55$ & & 0.022 & & & \\
\hline $\mathrm{Hb}(\mathrm{mmol} / \mathrm{L})$ & & & & & 0.483 & 0.302 & 0.212 & 0.678 & 0.695 \\
\hline \multirow[t]{2}{*}{ Norm } & VCV & $5.81 \pm 0.91$ & $5.64 \pm 0.95$ & $5.75 \pm 1$ & & & & & \\
\hline & FCV & $5.92 \pm 1.05$ & $5.78 \pm 1.07$ & $5.69 \pm 0.85$ & & & & & \\
\hline \multirow[t]{2}{*}{ Нуро } & VCV & $5.19 \pm 0.97$ & $5.11 \pm 0.98$ & $5.14 \pm 0.91$ & & & & & \\
\hline & FCV & $5.46 \pm 0.95$ & $5.45 \pm 0.94$ & $5.44 \pm 0.87$ & & & & & \\
\hline Shunt (\%) & & & & & 0.944 & 0.103 & 0.097 & 0.050 & 0.114 \\
\hline \multirow[t]{2}{*}{ Norm } & VCV & $32.8 \pm 11.1$ & $29.8 \pm 8.9$ & $29.9 \pm 10.2$ & & & & & \\
\hline & FCV & $32.5 \pm 8.2$ & $32.2 \pm 7.7$ & $30.8 \pm 8.2$ & & & & & \\
\hline \multirow[t]{2}{*}{ Нyро } & VCV & $41.7 \pm 11.3$ & $40.2 \pm 11.6$ & $38.3 \pm 10.4$ & & & & & \\
\hline & FCV & $37 \pm 9.8$ & $37.7 \pm 10.5$ & $39.6 \pm 12.1$ & & & & & \\
\hline
\end{tabular}

Values in mean \pm standard deviation; Statistical $P$ values according to linear mixed-effects repeated measures ANOVA with with-in subject factors: mode of ventilation (volume or flow-controlled ventilation) and time of therapy in minutes; and between subject factors group of therapy (normovolaemia or hypovolaemia) and randomisation sequence (volume or flow-controlled ventilation first). Significance was accepted for $P<0.05$. Statistical analysis was performed in $\mathrm{R}$ statistical programming language and the package Ime4 FCV flow-controlled ventilation, VCV volume-controlled ventilation, MAP mean arterial pressure, MPAP mean pulmonary arterial pressure, CVP central venous pressure, CO cardiac output, EVLW extravascular lung water, ITBV intrathoracic blood volume, GEDV global end-diastolic volume, SVR systemic vascular resistance, $\mathrm{Hb}$ haemoglobin, Shunt intrapulmonary shunt

intrapulmonary shunt was reduced and $\mathrm{PaO}_{2}$ increased. Another possible reason is that VCV resulted in higher total PEEP during VCV than FCV in our animals. Intrinsic PEEP can be more effectively avoided during FCV due to the active control of the expiration by the ventilator, while a passive expiratory flow combined with a relatively narrow inner diameter of the double-lumen tube during VCV led to an unintended increase of intrinsic PEEP [29]. The higher intrinsic PEEP during VCV may have led to air trapping, which can improve oxygenation, but not necessarily ventilation. In fact, the EIT analysis showed that the distribution of ventilation did not differ significantly between VCV and FC, which is in line with the regional distribution of end-expiratory pleural and transpulmonary pressures that did not differ significantly between VCV and FCV. In contrast to the present study, in pigs with non-injured and injured lungs, FCV led to a shift of regional ventilation towards dependent lung areas [11]. However, in that study, $P_{\text {mean }}$ was also higher during FCV than VCV [11].

Our finding that $\mathrm{PaCO}_{2}$ did not differ between FCV and VCV is in line with a previous study in pigs with non-injured lungs [10]. Nevertheless, in our study, the minute volume was markedly lower during FCV than VCV, yielding a higher ventilation efficiency under normovolaemia, and suggesting a lower alveolar dead-space ventilation during FCV. This is supported by the fact that the pulmonary shunt was not different between groups. The increased ventilation efficiency of FCV might be explained by improved emptying of lung units with different time constants at lower expiratory flow. Moreover, expiratory alveolar pressure is kept for a longer time above the alveolar closing pressure at the lower constant expiratory flow. However, we cannot completely rule out the possibility that a reduction in the anatomic dead space due to the relatively small inner diameter of the Tritube, as compared to the inner diameter of the doublelumen tube, also contributed to this effect. During hypovolaemia, ventilation efficiency 
Table 2 Respiratory parameters

\begin{tabular}{|c|c|c|c|c|c|c|c|c|c|}
\hline \multirow{2}{*}{$\begin{array}{l}\text { Parameter } \\
\text { Group }\end{array}$} & \multicolumn{4}{|c|}{ Therapy } & \multicolumn{5}{|c|}{ ANOVA $(P=)$} \\
\hline & Mode & $20^{\prime}$ & $40^{\prime}$ & $60^{\prime}$ & Seq & Group & Mode & Time & Mixed \\
\hline $\mathrm{V}_{\mathrm{T}}(\mathrm{mL} / \mathrm{kg})$ & & & & & 0.006 & 0.730 & 0.049 & 0.648 & 0.137 \\
\hline \multirow[t]{3}{*}{ Norm } & VCV & $5.1 \pm 0.2$ & $5.1 \pm 0.2$ & $5.1 \pm 0.2$ & & & 0.042 & 0.978 & 0.044 \\
\hline & FCV & $5.4 \pm 0.3$ & $5.6 \pm 0.2$ & $5.6 \pm 0.2$ & & & & & \\
\hline & & $P=0.020$ & $P<0.001$ & $P<0.001$ & & & & & \\
\hline \multirow[t]{2}{*}{ Hypo } & VCV & $5.1 \pm 0.3$ & $5.1 \pm 0.3$ & $5.0 \pm 0.3$ & & & 0.251 & 0.621 & 0.532 \\
\hline & FCV & $5.4 \pm 0.2$ & $5.5 \pm 0.3$ & $5.5 \pm 0.4$ & & & & & \\
\hline MV (L/min) & & & & & 0.520 & 0.799 & $<0.001$ & 0.904 & 0.570 \\
\hline \multirow[t]{3}{*}{ Norm } & VCV & $7.7 \pm 0.5$ & $7.7 \pm 0.5$ & $7.7 \pm 0.5$ & & & $<0.001$ & 0.894 & 0.995 \\
\hline & FCV & $6.8 \pm 0.2$ & $6.8 \pm 0.4$ & $6.8 \pm 0.4$ & & & & & \\
\hline & & $P<0.001$ & $P<0.001$ & $P<0.001$ & & & & & \\
\hline \multirow[t]{3}{*}{ Нyро } & VCV & $7.8 \pm 0.7$ & $7.8 \pm 0.8$ & $7.8 \pm 0.8$ & & & $<0.001$ & 0.778 & 0.453 \\
\hline & FCV & $6.8 \pm 1.0$ & $7 \pm 0.8$ & $7.0 \pm 0.8$ & & & & & \\
\hline & & $P<0.001$ & $P=0.008$ & $P=0.002$ & & & & & \\
\hline $\mathrm{RR}\left(\min ^{-1}\right)$ & & & & & 0.897 & 0.495 & $<0.001$ & 0.989 & 0.403 \\
\hline \multirow[t]{3}{*}{ Norm } & VCV & $35 \pm 0$ & $35 \pm 0$ & $35 \pm 0$ & & & $<0.001$ & 0.983 & 0.145 \\
\hline & FCV & $29 \pm 1$ & $28 \pm 1$ & $29 \pm 1$ & & & & & \\
\hline & & $P<0.001$ & $P<0.001$ & $P<0.001$ & & & & & \\
\hline \multirow[t]{3}{*}{ Hypo } & VCV & $35 \pm 0$ & $35 \pm 0$ & $35 \pm 0$ & & & $<0.001$ & 0.999 & 0.990 \\
\hline & FCV & $28 \pm 2$ & $29 \pm 2$ & $28 \pm 2$ & & & & & \\
\hline & & $P<0.001$ & $P<0.001$ & $P<0.001$ & & & & & \\
\hline Pmean $\left(\mathrm{cmH}_{2} \mathrm{O}\right)$ & & & & & 0.345 & 0.666 & 0.731 & 0.756 & 0.098 \\
\hline \multirow[t]{2}{*}{ Norm } & VCV & $15.1 \pm 1.1$ & $14.8 \pm 1.0$ & $14.8 \pm 1.1$ & & & & & \\
\hline & FCV & $15.3 \pm 1.3$ & $16 \pm 1.4$ & $15.9 \pm 1.1$ & & & & & \\
\hline \multirow[t]{2}{*}{ Hypo } & VCV & $14.6 \pm 1.8$ & $14.8 \pm 1.8$ & $14.8 \pm 1.8$ & & & & & \\
\hline & FCV & $14.9 \pm 3.3$ & $14.8 \pm 3.2$ & $15.6 \pm 3.4$ & & & & & \\
\hline Ppeak $\left(\mathrm{cmH}_{2} \mathrm{O}\right)$ & & & & & 0.498 & 0.467 & $<0.001$ & 0.661 & 0.419 \\
\hline \multirow[t]{3}{*}{ Norm } & VCV & $33 \pm 3.1$ & $32.3 \pm 3.4$ & $32.4 \pm 3.3$ & & & $<0.001$ & 0.590 & 0.082 \\
\hline & FCV & $28 \pm 3.4$ & $29.6 \pm 3.4$ & $29.8 \pm 3.4$ & & & & & \\
\hline & & $P=0.009$ & $P=0.133$ & $P=0.143$ & & & & & \\
\hline \multirow[t]{3}{*}{ Hypo } & VCV & $31.3 \pm 3.4$ & $31.8 \pm 3.3$ & $32.5 \pm 4.3$ & & & 0.027 & 0.315 & 0.715 \\
\hline & FCV & $27.4 \pm 5.8$ & $26.5 \pm 5.3$ & $28 \pm 4.8$ & & & & & \\
\hline & & $P=0.125$ & $P=0.033$ & $P=0.065$ & & & & & \\
\hline PEEP $\left(\mathrm{cmH}_{2} \mathrm{O}\right)$ & & & & & 0.265 & 0.141 & 0.002 & 0.977 & 0.634 \\
\hline \multirow[t]{3}{*}{ Norm } & VCV & $5.1 \pm 0.4$ & $5.1 \pm 0.4$ & $5.1 \pm 0.3$ & & & $<0.001$ & 0.941 & 0.955 \\
\hline & FCV & $4.2 \pm 0.2$ & $4.3 \pm 0.1$ & $4.2 \pm 0.2$ & & & & & \\
\hline & & $P<0.001$ & $P<0.001$ & $P<0.001$ & & & & & \\
\hline \multirow[t]{2}{*}{ Hypo } & VCV & $4.9 \pm 0.4$ & $4.8 \pm 0.3$ & $4.9 \pm 0.2$ & & & 0.111 & 0.994 & 0.634 \\
\hline & FCV & $3.7 \pm 1.3$ & $4 \pm 1.2$ & $3.5 \pm 1.6$ & & & & & \\
\hline Total PEEP $\left(\mathrm{cmH}_{2} \mathrm{O}\right)$ & & & & & 0.386 & 0.947 & $<0.001$ & 0.885 & 0.420 \\
\hline \multirow[t]{3}{*}{ Norm } & VCV & $6.2 \pm 0.6$ & $6.3 \pm 0.7$ & $6.3 \pm 0.7$ & & & $<0.001$ & 0.671 & 0.552 \\
\hline & FCV & $4.43 \pm 0.1$ & $4.4 \pm 0.1$ & $4.3 \pm 0.1$ & & & & & \\
\hline & & $P<0.001$ & $P<0.001$ & $P<0.001$ & & & & & \\
\hline Нyро & VCV & $6.6 \pm 1.0$ & $6.5 \pm 0.7$ & $6.5 \pm 0.8$ & & & $<0.001$ & 0.906 & 0.560 \\
\hline
\end{tabular}


Table 2 Respiratory parameters (Continued)

\begin{tabular}{|c|c|c|c|c|c|c|c|c|c|}
\hline \multirow{2}{*}{$\begin{array}{l}\text { Parameter } \\
\text { Group }\end{array}$} & \multicolumn{4}{|c|}{ Therapy } & \multicolumn{5}{|c|}{ ANOVA $(P=)$} \\
\hline & Mode & $20^{\prime}$ & $40^{\prime}$ & $60^{\prime}$ & Seq & Group & Mode & Time & Mixed \\
\hline & FCV & $4.2 \pm 0.9$ & $4.4 \pm 0.9$ & $4.0 \pm 1.0$ & & & & & \\
\hline & & $P<0.001$ & $P<0.001$ & $P<0.001$ & & & & & \\
\hline
\end{tabular}

Values in mean \pm standard deviation; Statistical $P$ values according to linear mixed-effects repeated measures ANOVA with within subject factors: mode of ventilation (volume or flow-controlled ventilation) and time of therapy in minutes; and between subject factors group of therapy (normovolaemia or hypovolaemia) and randomisation sequence (volume or flow-controlled ventilation first). Significance was accepted for $P<0.05$. Statistical analysis was performed in $\mathrm{R}$ Statistical programming language and the package Ime4

FCV flow-controlled ventilation, $V C V$ volume-controlled ventilation, $V_{T}$ tidal volume, $M V$ minute volume, $R R$ respiratory rate, $P_{\text {mean }}$ mean tracheal pressure, $P_{\text {peak }}$ peak tracheal pressure, $P E E P$ positive end-expiratory pressure, total PEEP PEEP + intrinsic PEEP

Table 3 Respiratory mechanics and mechanical power

\begin{tabular}{|c|c|c|c|c|c|c|c|c|c|}
\hline \multirow{2}{*}{$\begin{array}{l}\text { Parameter } \\
\text { Group }\end{array}$} & \multicolumn{4}{|c|}{ Therapy } & \multicolumn{5}{|c|}{ ANOVA $(P=)$} \\
\hline & Mode & $20^{\prime}$ & $40^{\prime}$ & $60^{\prime}$ & Seq & Group & Mode & Time & Mixed \\
\hline $\mathrm{R}\left(\mathrm{cmH}_{2} \mathrm{O} \mathrm{s} / \mathrm{L}\right)$ & & & & & 0.171 & 0.531 & $<0.001$ & 1.000 & 0.896 \\
\hline \multirow[t]{3}{*}{ Norm } & VCV & $32.7 \pm 7.59$ & $33.3 \pm 7.81$ & $32.8 \pm 7.53$ & & & $<0.001$ & 0.977 & 0.963 \\
\hline & FCV & $7.26 \pm 0.973$ & $8.1 \pm 3.29$ & $7.47 \pm 1.73$ & & & & & \\
\hline & & $P<0.001$ & $P<0.001$ & $P<0.001$ & & & & & \\
\hline \multirow[t]{3}{*}{ Hypo } & VCV & $35 \pm 9.18$ & $34.5 \pm 11$ & $34.9 \pm 11.1$ & & & $<0.001$ & 0.986 & 0.860 \\
\hline & FCV & $8.58 \pm 8.49$ & $8.08 \pm 6.78$ & $7.44 \pm 6.26$ & & & & & \\
\hline & & $P=0.003$ & $P=0.004$ & $P=0.003$ & & & & & \\
\hline $\mathrm{C}\left(\mathrm{mL} / \mathrm{cmH}_{2} \mathrm{O}\right)$ & & & & & 0.882 & 0.142 & 0.006 & 0.980 & 0.860 \\
\hline \multirow[t]{2}{*}{ Norm } & VCV & $11 \pm 1.77$ & $11.7 \pm 2.06$ & $11.6 \pm 2.19$ & & & 0.050 & 0.347 & 0.849 \\
\hline & FCV & $9.34 \pm 1.61$ & $9.7 \pm 1.23$ & $9.72 \pm 1.57$ & & & & & \\
\hline \multirow[t]{3}{*}{ Нypo } & VCV & $12.9 \pm 2.36$ & $12.3 \pm 2.13$ & $12.3 \pm 2.29$ & & & 0.037 & 0.175 & 0.969 \\
\hline & FCV & $11.5 \pm 2.13$ & $11 \pm 1.8$ & $10.9 \pm 1.63$ & & & & & \\
\hline & & $P=0.042$ & $P=0.013$ & $P=0.041$ & & & & & \\
\hline$M P_{\text {resis }}(\mathrm{J} / \mathrm{min})$ & & & & & 0.375 & 0.521 & $<0.001$ & 0.840 & 0.901 \\
\hline \multirow[t]{3}{*}{ Norm } & VCV & $6.5 \pm 1.3$ & $6.6 \pm 1.4$ & $6.4 \pm 1.4$ & & & $<0.001$ & 0.855 & 0.787 \\
\hline & FCV & $1.2 \pm 0.2$ & $1.3 \pm 0.4$ & $1.3 \pm 0.3$ & & & & & \\
\hline & & $P<0.001$ & $P<0.001$ & $P<0.001$ & & & & & \\
\hline \multirow[t]{3}{*}{ Hypo } & VCV & $7.2 \pm 2.1$ & $7.0 \pm 2.3$ & $7.1 \pm 2.3$ & & & $<0.001$ & 0.899 & 0.992 \\
\hline & FCV & $1.3 \pm 0.9$ & $1.2 \pm 0.7$ & $1.2 \pm 0.7$ & & & & & \\
\hline & & $P<0.001$ & $P=0.001$ & $P<0.001$ & & & & & \\
\hline $\mathrm{MP}_{\text {elas }}(\mathrm{J} / \mathrm{min})$ & & & & & 0.392 & 0.437 & 0.243 & 0.931 & 0.206 \\
\hline \multirow[t]{2}{*}{ Norm } & VCV & $7.6 \pm 1.2$ & $7.4 \pm 1.4$ & $7.4 \pm 1.4$ & & & & & \\
\hline & FCV & $8.4 \pm 1.4$ & $8.7 \pm 1.6$ & $8.9 \pm 1.7$ & & & & & \\
\hline \multirow[t]{2}{*}{ Hypo } & VCV & $6.9 \pm 1.8$ & $7.1 \pm 1.5$ & $7.1 \pm 1.5$ & & & & & \\
\hline & FCV & $7.5 \pm 2.9$ & $8.0 \pm 2.4$ & $8.1 \pm 2.5$ & & & & & \\
\hline
\end{tabular}

Values in mean \pm standard deviation; Statistical $P$ values according to linear mixed-effects repeated-measures ANOVA with within subject factors: mode of ventilation (volume or flow-controlled ventilation) and time of therapy in minutes; and between subject factors group of therapy (normovolaemia or hypovolaemia) and randomisation sequence (volume or flow-controlled ventilation first). Significance was accepted for $P<0.05$. Statistical analysis was performed in $\mathrm{R}$ statistical programming language and the package Ime4.

FCV flow-controlled ventilation, VCV volume-controlled ventilation, $C$ compliance of the respiratory system, $M P_{\text {resis }}$ resistive mechanical power, $M P_{\text {elas }}$ elastic mechanical power 


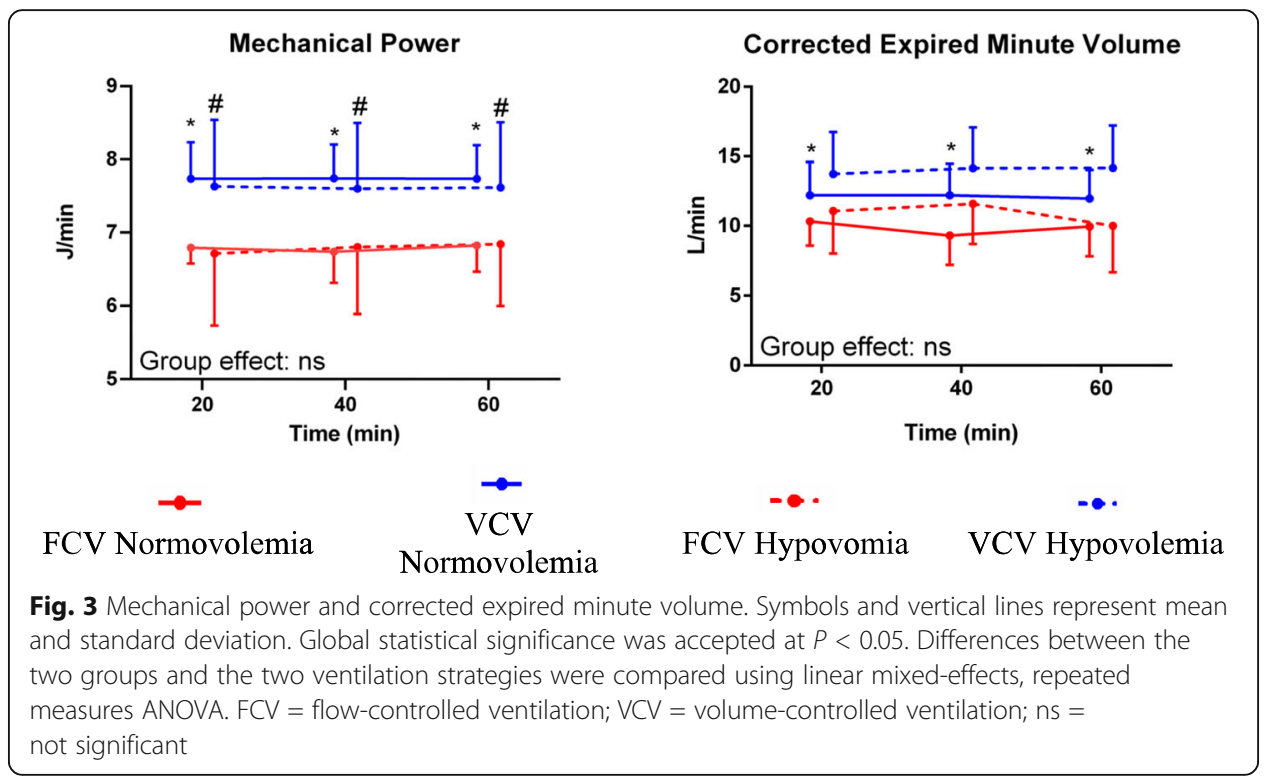

was not different between FCV and VCV. This might be explained by the fact that alveolar dead space is increased due to pulmonary hypoperfusion secondary to hypovolaemia [30] blunting possible positive effects of expiratory flow control.

In the present study, the haemodynamic impact of FCV and VCV did not differ significantly, irrespective of the volaemia status. Contrastingly in pigs with hypovolaemia induced by haemorrhage, FCV improved venous return and cardiac output compared to VCV [31]. However, differently from the present investigation, the end-expiratory pressure during FCV was negative in that study, while our animals were ventilated with a PEEP of $5 \mathrm{cmH}_{2} \mathrm{O}$ in both ventilation modes.

Our discovery that the compliance of the respiratory system was similar for FCV and VCV during normovolaemia is in line with other experimental studies [10, 11]. However, in the hypovolaemia group, compliance was lower for FCV as compared with VCV. This might be explained by a higher total PEEP during VCV, which can result in a shift on the pressure-volume curve to a more compliant region of the lung during VCV.

Our finding that FCV reduced the resistance of the respiratory system compared with $\mathrm{VCV}$ is in line with previous reports $[12,28]$. In this manner, FCV also reduced mechanical power and resistive mechanical power compared to VCV. This reduction is particularly important since during OLV resistance is increased already due to decreased lung volume, the lateral decubitus position and the displacement of the diaphragm and the mediastinum and further rises depending on the gas flow. High-resistive mechanical power due to high gas flow, as found during VCV, can be associated with shear stress at the top of the cells within the respiratory bronchi [32] and therefore with increased risk for lung damage $[5,33]$. Resistive mechanical power relates to the inspiratory phase only. However, the energy accumulated at end-inspiration will be dissipated both into the lung structures and into the atmosphere at end-expiration. Since inspiration and expiration showed similar constant low flow profiles during FCV, the amount of resistive energy dissipated in the lungs during a ventilation cycle was most likely further minimised. In fact, in a porcine acute lung injury model flow-controlled expiration resulted in reduced ventilator-induced lung injury [34]. 
Table 4 Regional end-expiratory pleural and transpulmonary pressures

\begin{tabular}{|c|c|c|c|c|c|c|c|c|c|}
\hline \multirow{2}{*}{$\begin{array}{l}\text { Parameter } \\
\text { Group }\end{array}$} & \multicolumn{4}{|c|}{ Therapy } & \multicolumn{5}{|c|}{ ANOVA $(P=)$} \\
\hline & Mode & $20^{\prime}$ & $40^{\prime}$ & $60^{\prime}$ & $\overline{\text { Seq }}$ & Group & Mode & Time & Mixed \\
\hline PPvent $\left(\mathrm{cmH}_{2} \mathrm{O}\right)$ & & & & & 0.073 & 0.994 & 0.022 & 0.437 & 0.116 \\
\hline \multirow[t]{2}{*}{ Norm } & VCV & $0.1 \pm 2.6$ & $-0.1 \pm 2.7$ & $-0.0 \pm 3.2$ & & & 0.076 & 0.866 & 0.256 \\
\hline & FCV & $-1.3 \pm 3.6$ & $-1.0 \pm 3.4$ & $-0.2 \pm 3.5$ & & & & & \\
\hline \multirow[t]{2}{*}{ Нyро } & VCV & $0.3 \pm 0.7$ & $-0.6 \pm 2.4$ & $-0.3 \pm 2.9$ & & & 0.161 & 0.327 & 0.288 \\
\hline & FCV & $-0.7 \pm 2.1$ & $-0.9 \pm 3.0$ & $-0.3 \pm 1.7$ & & & & & \\
\hline PPdors $\left(\mathrm{cmH}_{2} \mathrm{O}\right)$ & & & & & 0.054 & 0.079 & 0.975 & 0.045 & 0.744 \\
\hline \multirow[t]{2}{*}{ Norm } & VCV & $-1.9 \pm 3.1$ & $-1.5 \pm 4.1$ & $0.1 \pm 3.0$ & & & & & \\
\hline & FCV & $-1.0 \pm 3.1$ & $-1.6 \pm 3.7$ & $-0.8 \pm 2.9$ & & & & & \\
\hline \multirow[t]{2}{*}{ Нyро } & VCV & $0.9 \pm 0.7$ & $0.6 \pm 1.5$ & $1.1 \pm 0.8$ & & & & & \\
\hline & FCV & $-0.3 \pm 3.2$ & $0.6 \pm 0.9$ & $1.1 \pm 0.8$ & & & & & \\
\hline PPcaud $\left(\mathrm{cmH}_{2} \mathrm{O}\right)$ & & & & & 0.754 & 0.109 & 0.211 & 0.202 & 0.447 \\
\hline \multirow[t]{2}{*}{ Norm } & VCV & $-0.2 \pm 3.2$ & $-0.7 \pm 3.5$ & $0.1 \pm 3.3$ & & & & & \\
\hline & FCV & $-1.8 \pm 4$ & $-0.8 \pm 3.4$ & $-0.0 \pm 3.4$ & & & & & \\
\hline \multirow[t]{2}{*}{ Hypo } & VCV & $1.0 \pm 2.0$ & $1.9 \pm 1.4$ & $1.7 \pm 1.3$ & & & & & \\
\hline & FCV & $1.3 \pm 1.6$ & $1.5 \pm 1.4$ & $1.5 \pm 1.6$ & & & & & \\
\hline TPvent $\left(\mathrm{cmH}_{2} \mathrm{O}\right)$ & & & & & 0.103 & 0.970 & 0.262 & 0.461 & 0.076 \\
\hline \multirow[t]{2}{*}{ Norm } & VCV & $5.4 \pm 2.5$ & $5.6 \pm 2.8$ & $5.4 \pm 3.1$ & & & & & \\
\hline & FCV & $5.8 \pm 3.5$ & $5.3 \pm 3.2$ & $4.5 \pm 3.2$ & & & & & \\
\hline \multirow[t]{2}{*}{ Hypo } & VCV & $5.11 \pm 0.7$ & $6 \pm 2.4$ & $5.7 \pm 2.8$ & & & & & \\
\hline & FCV & $5.22 \pm 2.2$ & $5.4 \pm 3.0$ & $4.8 \pm 1.6$ & & & & & \\
\hline TPdors $\left(\mathrm{cmH}_{2} \mathrm{O}\right)$ & & & & & 0.092 & 0.098 & 0.347 & 0.036 & 0.984 \\
\hline \multirow[t]{2}{*}{ Norm } & VCV & $7.3 \pm 3.0$ & $7.0 \pm 4.4$ & $5.3 \pm 2.8$ & & & & & \\
\hline & FCV & $5.8 \pm 3.5$ & $5.5 \pm 3.2$ & $5 \pm 2.7$ & & & & & \\
\hline \multirow[t]{2}{*}{ Hypo } & VCV & $4.5 \pm 0.6$ & $4.8 \pm 1.6$ & $4.3 \pm 0.8$ & & & & & \\
\hline & FCV & $4.9 \pm 2.8$ & $3.9 \pm 0.8$ & $3.36 \pm 1.3$ & & & & & \\
\hline TPcaud $\left(\mathrm{cmH}_{2} \mathrm{O}\right)$ & & & & & 0.626 & 0.060 & 0.839 & 0.311 & 0.953 \\
\hline \multirow[t]{2}{*}{ Norm } & VCV & $5.8 \pm 3.0$ & $6.1 \pm 3.6$ & $5.3 \pm 3.2$ & & & & & \\
\hline & FCV & $6.6 \pm 4.4$ & $6.0 \pm 3.9$ & $5.6 \pm 4.4$ & & & & & \\
\hline \multirow[t]{2}{*}{ Hypo } & VCV & $4.4 \pm 1.9$ & $3.5 \pm 1.3$ & $3.7 \pm 1.2$ & & & & & \\
\hline & FCV & $3.2 \pm 1.8$ & $3.0 \pm 1.6$ & $3.0 \pm 2.0$ & & & & & \\
\hline
\end{tabular}

Values in mean \pm standard deviation; Statistical $P$ values according to linear mixed-effects repeated measures ANOVA with within subject factors: mode of ventilation (volume or flow-controlled ventilation) and time of therapy in minutes; and between subject factors group of therapy (normovolaemia or hypovolaemia) and randomization sequence (volume or flow-controlled ventilation first). Significance was accepted for $P<0.05$. Statistical analysis was performed in $\mathrm{R}$ statistical programming language and the package Ime4

FCV flow-controlled ventilation, VCV volume-controlled ventilation, PIPvent end-expiratory ventral pleural pressure, PIPdors end-expiratory dorsal pleural pressure, PIPcaud end-expiratory caudal pleural pressure, TPvent end-expiratory ventral transpulmonary pressure, TPdors end-expiratory dorsal transpulmonary pressure, TPcaud end-expiratory caudal transpulmonary pressure

\section{Potential implications of these findings}

OLV is associated with an increased risk of hypoxemia and VILI formation. A mode of ventilation that avoids both is urgently needed. The present findings suggest that FCV in OLV maintains gas exchange while reducing mechanical stress on the lungs, possibly reducing postoperative pulmonary complications. Further studies are necessary to clarify whether these physiological benefits also lead to a better clinical outcome. 
Table 5 Distribution of tidal impedance changes and centre of ventilation in the therapy lung

\begin{tabular}{|c|c|c|c|c|c|c|c|c|c|}
\hline \multirow{2}{*}{$\begin{array}{l}\text { Parameter } \\
\text { Group }\end{array}$} & \multirow[t]{2}{*}{ Mode } & \multicolumn{3}{|l|}{ Therapy } & \multicolumn{5}{|c|}{ ANOVA $(P=)$} \\
\hline & & $20^{\prime}$ & $40^{\prime}$ & $60^{\prime}$ & Seq & Group & Mode & Time & Mixed \\
\hline \multicolumn{5}{|l|}{ Indepen (\%) } & 0.791 & 0.596 & 0.238 & 0.291 & 0.791 \\
\hline \multirow[t]{2}{*}{ Normo } & VCV & $41.4 \pm 8.71$ & $41.5 \pm 8.45$ & $41.9 \pm 8.47$ & & & & & \\
\hline & FCV & $41.1 \pm 10.5$ & $42.7 \pm 10.8$ & $44 \pm 10.4$ & & & & & \\
\hline \multirow[t]{2}{*}{ Нyро } & VCV & $39.1 \pm 11$ & $39.4 \pm 10.9$ & $38.4 \pm 11.3$ & & & & & \\
\hline & FCV & $39.1 \pm 11.9$ & $39.7 \pm 12.2$ & $40.1 \pm 12.8$ & & & & & \\
\hline \multicolumn{2}{|l|}{ Semidep (\%) } & & & & 0.922 & 0.616 & 0.145 & 0.437 & 0.127 \\
\hline \multirow[t]{2}{*}{ Normo } & VCV & $56.3 \pm 7.61$ & $56.2 \pm 7.38$ & $55.7 \pm 7.34$ & & & & & \\
\hline & FCV & $56.4 \pm 9.59$ & $54.9 \pm 9.91$ & $53.6 \pm 9.62$ & & & & & \\
\hline \multirow[t]{2}{*}{ Нypo } & VCV & $58.1 \pm 10.2$ & $57.8 \pm 10.2$ & $58.4 \pm 10.2$ & & & & & \\
\hline & FCV & $58.1 \pm 11.2$ & $57.6 \pm 11.6$ & $57.3 \pm 12.3$ & & & & & \\
\hline \multicolumn{2}{|l|}{ Depend (\%) } & & & & 0.962 & 0.408 & 0.698 & 0.731 & 0.561 \\
\hline \multirow[t]{2}{*}{ Normo } & VCV & $2.28 \pm 1.25$ & $2.29 \pm 1.23$ & $2.31 \pm 1.33$ & & & & & \\
\hline & FCV & $2.53 \pm 1.07$ & $2.4 \pm 0.974$ & $2.4 \pm 0.927$ & & & & & \\
\hline \multirow[t]{2}{*}{ Нypo } & VCV & $2.83 \pm 1.69$ & $2.83 \pm 1.76$ & $2.57 \pm 1.75$ & & & & & \\
\hline & FCV & $2.8 \pm 1.56$ & $2.63 \pm 1.55$ & $2.58 \pm 1.55$ & & & & & \\
\hline \multicolumn{3}{|c|}{ Centre of ventilation (\%) } & & & 0.208 & 0.585 & 0.103 & 0.090 & 0.208 \\
\hline \multirow[t]{2}{*}{ Normo } & VCV & $60.5 \pm 3.88$ & $60.5 \pm 3.77$ & $61.2 \pm 3.16$ & & & & & \\
\hline & FCV & $60.8 \pm 3.51$ & $62.2 \pm 2.63$ & $62.3 \pm 3.09$ & & & & & \\
\hline \multirow[t]{2}{*}{ Hypo } & VCV & $60.2 \pm 4.28$ & $60.4 \pm 4.46$ & $60.3 \pm 4.68$ & & & & & \\
\hline & FCV & $60.3 \pm 5.02$ & $60 \pm 4.03$ & $60.4 \pm 3.92$ & & & & & \\
\hline
\end{tabular}

Values in mean \pm standard deviation; Statistical $P$ values according to linear mixed-effects repeated measures ANOVA with within subject factors: mode of ventilation (volume or flow-controlled ventilation) and time of therapy in minutes; and between subject factors group of therapy (normovolaemia or hypovolaemia) and randomization sequence (volume or flow-controlled ventilation first). Significance was accepted for $P<0.05$. Statistical analysis was performed in $R$ statistical programming language and the package Ime4

FCV flow-controlled ventilation, VCV volume-controlled ventilation, Indep independent lung regions, semidep semidependent lung regions, dpend dependent lung regions. Centre of ventilation was calculated with the base at dorsal part of the lung. $0 \%$ would mean ventilation (change of impedance due to ventilation) is concentrated on the most dependent layer

\section{Limitations}

The present study knows several limitations. First, the used thoracic surgery model does not fully represent the clinical scenario, especially due to the lack of surgical manipulation of the lungs and its potential effects on atelectasis in the dependent lung. Thus, we cannot extrapolate our findings directly to patients. Second, we addressed only short-term effects of FCV and VCV during OLV. Nevertheless, one-lung ventilation is usually limited to short time periods. Third, we did not assess gas exchange variables at 30 minutes after initiation of OLV, when the hypoxic pulmonary vasoconstriction reaches a maximum [13]. However, if an effect in gas exchange was overseen, the importance of such effect is questionable. Fourth, the crossover design of our study precluded the comparison of effects of ventilation modes on VILI. Thus, we do not know whether reduced mechanical power would translate into less lung damage.

\section{Conclusions}

In a model of OLV in normo- and hypovolemic pigs, mechanical power was lower during FCV compared to VCV, without significant differences in oxygenation. Furthermore, the efficacy of ventilation was higher during FCV compared to VCV during normovolaemia. 


\section{Abbreviations}

C: Compliance of the respiratory system; CO: Cardiac output; EIT: Electrical impedance tomography; EVLW: Extravascular lung water; FCV: Flow-controlled ventilation; FIO2: Inspired fraction of oxygen; GEDV: Global enddiastolic volume; I:E: Inspiratory to expiratory time ratio; IPPV: Intermittent positive pressure ventilation;

ITBV: Intrathoracic blood volume; LPS: Lipopolysaccharide; MP: Mechanical power; MPresis: Resistive mechanical power; MPelas: Elastic mechanical power; MV: Minute volume; OLV: One-lung ventilation; PEEP: Positive end-expiratory pressure; PIP: Peak inspiratory pressure; Pmean: Mean tracheal pressure; PP: Pleural pressure; Ppeak: Peak tracheal pressure; R: Resistance of the respiratory system; RR: Respiratory rate; RR: Respiratory rate; SVR: Systemic vascular resistance; TLV: Two-lung ventilation; TP: Transpulmonary pressure; VCV: Volume-controlled ventilation; VILI: Ventilator-induced lung injury; VT: Tidal volume

\section{Acknowledgements}

We acknowledge the great help of Sabine Müller during the experiments. We thank her and the research fellows of the Pulmonary Engineering Group, University Hospital Carl Gustav Carus, Technische Universität Dresden, Germany, for their assistance in conducting the experiments. We thank Ventinova Medical for providing the ventilator.

\section{About this supplement}

This article has been published as part of Intensive Care Medicine Experimental Volume 8 Supplement 1, 2020: Proceedings from the Fourth International Symposium on Acute Pulmonary Injury and Translation Research (INSPIRES IV). The full contents of the supplement are available at https://icm-experimental.springeropen.com/articles/supplements/volume-8supplement-1.

\section{Authors' contributions}

JW, MS, XR, TKi, TB, MGA and RH designed the study. JW, MS, XR, DK, PM, ST, RT and RH conducted the experiments. $J W, M S, X R, D K, P H, R H, T K i, T B, T K o, M G A$ and $R H$ were involved in the analyses and the writing of the manuscript. The authors read and approved the final manuscript.

\section{Funding}

Ventinova Medical provided the ventilator Evone including the necessary supplies. Publication costs are funded by the INSPIRES steering committee.

\section{Availability of data and materials}

The datasets used and/or analysed during the current study are available from the corresponding author on reasonable request.

\section{Ethics approval and consent to participate}

The protocol of this study was approved by the local animal welfare committee as an amendment to experimental study (DD24.1-5131/449/71).

\section{Consent for publication}

Not applicable

\section{Competing interests}

The authors declare that they have no competing interests

Received: 14 July 2020 Accepted: 16 July 2020

Published: 18 December 2020

\section{References}

1. Liu TJ, Shih MS, Lee WL et al (2013) Hypoxemia during one-lung ventilation for robot-assisted coronary artery bypass graft surgery. The Annals of thoracic surgery 96:127-132

2. Senturk M, Slinger P, Cohen E (2015) Intraoperative mechanical ventilation strategies for one-lung ventilation. Best practice \& research. Clinical anaesthesiology 29:357-369

3. Lohser J, Slinger P (2015) Lung injury after one-lung ventilation: a review of the pathophysiologic mechanisms affecting the ventilated and the collapsed lung. Anesthesia and analgesia 121:302-318

4. Guldner A, Braune A, Ball L et al (2016) Comparative effects of volutrauma and atelectrauma on lung inflammation in experimental acute respiratory distress syndrome. Critical care medicine 44:e854-e865

5. Cressoni M, Gotti M, Chiurazzi C et al (2016) Mechanical power and development of ventilator-induced lung injury. Anesthesiology 124:1100-1108

6. Slutsky AS, Ranieri VM (2013) Ventilator-induced lung injury. The New England journal of medicine 369:2126-2136

7. Serpa Neto A, Hemmes SNT, Barbas CSV et al (2014) Incidence of mortality and morbidity related to postoperative lung injury in patients who have undergone abdominal or thoracic surgery: a systematic review and meta-analysis. Lancet. Respir. Med. 2:1007-1015

8. Investigators LV (2017) Epidemiology, practice of ventilation and outcome for patients at increased risk of postoperative pulmonary complications: LAS VEGAS - an observational study in 29 countries. European journal of anaesthesiology 34: $492-507$

9. Suki B, Barabasi AL, Hantos Z et al (1994) Avalanches and power-law behaviour in lung inflation. Nature 368:615-618

10. Schmidt J, Wenzel C, Mahn M et al (2018) Improved lung recruitment and oxygenation during mandatory ventilation with a new expiratory ventilation assistance device: a controlled interventional trial in healthy pigs. European journal of anaesthesiology 35:736-744 
11. Borgmann S, Schmidt J, Goebel U et al (2018) Dorsal recruitment with flow-controlled expiration (FLEX): an experimental study in mechanically ventilated lung-healthy and lung-injured pigs. Critical care 22:245

12. Barnes T, Enk D (2019) Ventilation for low dissipated energy achieved using flow control during both inspiration and expiration. Trends in Anaesthesia and Critical Care 24:5-12

13. Campos JH, Feider A (2018) Hypoxia during one-lung ventilation-a review and update. J Cardiothorac Vasc Anesth 32: 2330-2338

14. Hannon JP, Bossone CA, Wade CE (1990) Normal physiological values for conscious pigs used in biomedical-research. Laboratory animal science 40:293-298

15. Rohrer F (1915) Der Strömungswiderstand in den menschlichen Atemwegen und der Einfluss der unregelmässigen Verzweigung des Bronchialsystems auf den Atmungsverlauf in verschiedenen Lungenbezirken. Pflüger's Archiv für die Gesamte Physiologie des Menschen und der Thiere 162:225-299

16. Guttmann J, Eberhard L, Fabry B et al (1993) Continuous calculation of intratracheal pressure in tracheally intubated patients. Anesthesiology 79:503-513

17. Kiss T, Bluth T, Braune A et al (2019) Effects of positive end-expiratory pressure and spontaneous breathing activity on regional lung inflammation in experimental acute respiratory distress syndrome. Critical care medicine 47:e358-e365

18. Huhle R, Serpa Neto A, Schultz MJ et al (2018) Is mechanical power the final word on ventilator-induced lung injury?no. Annals of translational medicine 6:394

19. Sassoon CS, Mahutte CK (1998) Work of breathing during mechanical ventilation. In: Marini JJ, Slutsky A (eds) Physiological basis of ventilatroy support. Marcel Dekker, Inc., New York

20. Wexler HR, Lok P (1981) A simple formula for adjusting arterial carbon dioxide tension. Canadian Anaesthetists' Society journal 28:370-372

21. Bluth T, Kiss T, Kircher M et al (2019) Measurement of relative lung perfusion with electrical impedance and positron emission tomography: an experimental comparative study in pigs. British journal of anaesthesia 123:246-254

22. Team RC (2017) R: a language and environment for statistical computing. Austria, Vienna

23. Pinheiro J, Bates D, Debroy S et al. (2019) NLME: linear and nonlinear mixed effects models.

24. Lenth RV (2016) Least-squares means: the R package Ismeans. Journal of Statistical Software 69:1-33

25. Traber DL, Flynn JT, Herndon DN et al (1989) Comparison of the cardiopulmonary responses to single bolus and continuous infusion of endotoxin in an ovine model. Circ Shock 27:123-138

26. Silva PL, Guldner A, Uhlig C et al (2013) Effects of intravascular volume replacement on lung and kidney function and damage in nonseptic experimental lung injury. Anesthesiology 118:395-408

27. Nakamura H, Saji H, Kurimoto $\mathrm{N}$ et al (2015) Impact of intraoperative blood loss on long-term survival after lung cancer resection. Ann Thorac Cardiovasc Surg 21:18-23

28. Barnes T, Van Asseldonk D, Enk D (2018) Minimisation of dissipated energy in the airways during mechanical ventilation by using constant inspiratory and expiratory flows - flow-controlled ventilation (FCV). Med. Hypotheses 121:167-176

29. Spaeth J, Ott M, Karzai W et al (2016) Double-lumen tubes and auto-PEEP during one-lung ventilation. British journal of anaesthesia 116:122-130

30. Tusman G, Sipmann FS, Bohm SH (2012) Rationale of dead space measurement by volumetric capnography. Anesthesia and analgesia 114:866-874

31. Berlin DA, Manoach S, Oromendia C et al (2019) Automated expiratory ventilation assistance through a small endotracheal tube can improve venous return and cardiac output. Intensive care medicine experimental 7:6

32. Silva PL, Ball L, Rocco PRM et al (2019) Power to mechanical power to minimize ventilator-induced lung injury? Intensive care medicine experimental 7:38

33. Protti A, Maraffi T, Milesi M et al (2016) Role of strain rate in the pathogenesis of ventilator-induced lung edema. Critical care medicine 44:e838-e845

34. Goebel U, Haberstroh J, Foerster K et al (2014) Flow-controlled expiration: a novel ventilation mode to attenuate experimental porcine lung injury. British journal of anaesthesia 113:474-483

\section{Publisher's Note}

Springer Nature remains neutral with regard to jurisdictional claims in published maps and institutional affiliations.

\section{Submit your manuscript to a SpringerOpen ${ }^{\circ}$ journal and benefit from:}

- Convenient online submission

Rigorous peer review

Open access: articles freely available online

- High visibility within the field

- Retaining the copyright to your article

Submit your next manuscript at $\boldsymbol{\nabla}$ springeropen.com 